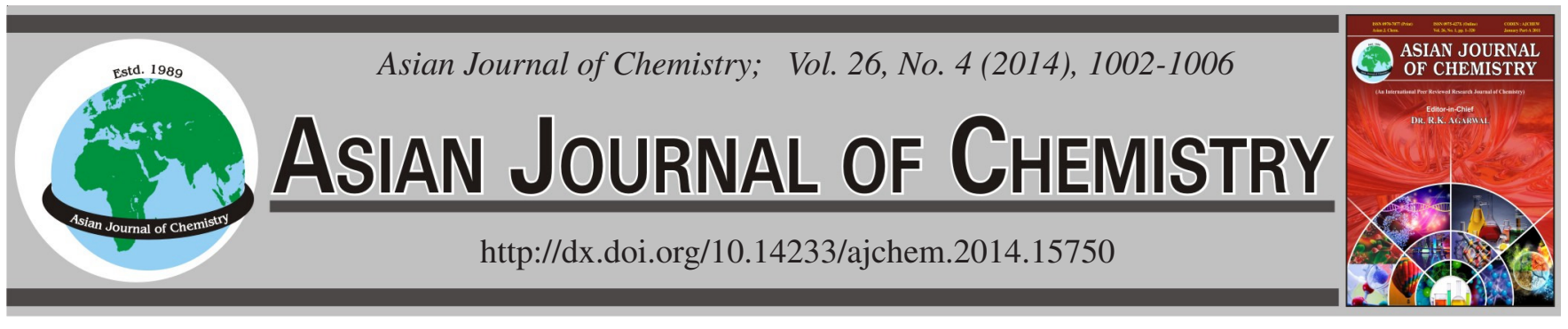

\title{
Gas Chromatographic Analysis of Automobile Gasoline and Lighter Gas Using Phenyl-Modified Aleppo Bentonite
}

\author{
Abdul Aziz Ramadan*, SaAd Antakli and Mohamad Subhi Sammani
}

Department of Chemistry, Faculty of Science, University of Aleppo, Aleppo, Syria

*Corresponding author: Fax: +96321 2633136; E-mail: dramadan@scs-net.org

Received: 9 May 2013;

Accepted: 12 June 2013;

Published online: 15 February 2014;

AJC-14687

Gas chromatographic analysis of automobile gasoline and lighter gas using phenyl-modified Aleppo bentonite was developed. The particles of Aleppo bentonite which have diameter $(150-250 \mu \mathrm{m})$ were thermally treated and washed by concentrated $\mathrm{HCl}$. Aleppo bentonite was grafted by dimethyldichlorosilane, then, it was reacted with phenyl magnesium bromide ( $\mathrm{B}_{\mathrm{A}}$ phenyl). The surface properties of $\mathrm{B}_{\mathrm{A}}$ and $\mathrm{B}_{\mathrm{A}}$ phenyl were characterized by nitrogen adsorption at $77 \mathrm{~K}$ and differential thermal analysis. It was found that, the BET surface areas $\left(\mathrm{S}_{\mathrm{BET}}\right)$ was 11.86 and $4.21 \mathrm{~m}^{2} / \mathrm{g}$, the total pore volume $\mathrm{v}_{\mathrm{p}}$ was $(0.0388$ and $0.01547 \mathrm{~mL} / \mathrm{g})$ and the mean pores radii $\mathrm{r}_{\mathrm{a}}$ were (65.43 and $73.49 \AA$ ) , respectively. Thirty six hydrocarbons components in gasoline and seven in lighter gas were determined by using $\mathrm{B}_{\mathrm{A}}$ phenyl as support in gas chromatographic analysis. The principle gasoline components groups (total $\mathrm{C}_{5}$ to total $\mathrm{C}_{10}$ ) were presented as follows: $0.001,0.28,14.76,34.16,13.07,25.13,11.59$ and $0.76 \%$ and lighter gas percent (propane, isobutane and $n$-butane) as follows: $3.03-48.49,29.03-45.75$ and $20.88-67.27 \%$, respectively.

Keywords: Phenyl-modified Aleppo bentonite, Gas chromatography, Gasoline, Lighter gas.

\section{INTRODUCTION}

Aleppo bentonite is rocky clay which consists of $47 \%$ $\mathrm{SiO}_{2}, 14.4 \% \mathrm{Al}_{2} \mathrm{O}_{3}$ and some other oxides as $\mathrm{Fe}_{2} \mathrm{O}_{3}, \mathrm{MgO}$, $\mathrm{CaO}, \mathrm{Na}_{2} \mathrm{O}$, etc. ${ }^{1,2}$. The thermal treatment causes decreasing of its specific surface area with increasing in the temperature of thermal treatment ${ }^{3,4}$. Bentonite clays are used in many industrial processes ${ }^{5,6}$ and it can be used as chromatographic supports in gas chromatography to separate many mixtures after grafting with different methods ${ }^{7,8}$. Bentonite is used as stationary phase in thin layer chromatography to separate some metal ions and vitamins $\mathrm{B}_{1}, \mathrm{~B}_{6}, \mathrm{~B}_{12}{ }^{9,10}$.

The surface properties of methyl- or octyl- or octadecylmodified bentonite using nitrogen adsorption (BET) at $77 \mathrm{~K}$, IR and differential thermal analysis (DTA) were studied. The surface areas $\left(\mathrm{S}_{\mathrm{BET}}\right)$, the mean pores radii $\left(\mathrm{r}_{\mathrm{a}}\right)$ and the total pore volumes were determined ${ }^{9,10}$.

Based on detailed hydrocarbon analysis of gasolines, their fractional composition were measured ${ }^{11-13}$. Knowing the qualitative and quantitative composition of the gasolines, one can determine the content of $n$-paraffin, isoparaffin, aromatic hydrocarbons, naphthene and olefin (PIANO) groups of hydrocarbons as well as of oxyorganic compounds (alcohols and ethers) used to raise the octane number ${ }^{14}$. The opportunity for solving similar problems arises from application of high- resolution capillary columns that allow completed separation of all hydrocarbons components. Analytical systems with such columns makes stringent demands on standards of data processing systems, especially on the algorithm for automatic identification of the components.

Tabular data of the main hydrocarbons in gasolines was collected and systematized. A procedure has been worked out for detailed analysis of the hydrocarbon compositions and calculation of the key characteristics of unethylated automobile gasolines. The methods of calculation of the complex characteristics of these gasolines have been programmed and the developed software package has been integrated into the system Unichrom- $97^{15}$.

An automatic method has been developed for the determination of gasoline components by gas chromatography. Separation has been achieved on squalane and cross-linked OV-1 capillary columns ${ }^{16}$. Analytical conditions were optimized and all peaks were identified. Programmed temperature indices were used for automatic identifications. These indices appear to be reproducible on different capillary columns having the same commercial specifications with identical analytical conditions $^{17,18}$.

Study has been conducted on motor gasoline and natural gas with applying gas chromatography and physical/chemical analysis using ethyl alcohol (oxygenates). The physical, 
chemical and gas chromatograph analysis are compared. The physical analysis revealed the basic role of adulteration and gas chromatograph analyses provided by the adulteration ${ }^{19-23}$.

This paper describes an automated method for the determination of gasoline and natural gas compounds by gas chromatographic analysis using packed column with support phenyl-modified Aleppo bentonite.

\section{EXPERIMENTAL}

The chromatograms were obtained by using a GC-9A gas chromatograph equipped with a flame ionization detector (FID) and chromatopac C-R3A printer (Shimadzu Co.), $1 \mu \mathrm{L}$ syringe (Hamilton Co.). Surface area and pore size measurement (BET) were recorded using Micromeritics Gemini III 2375 under nitrogen atmosphere (USA). Differential thermal analysis (DTA), LINSEIS type STA PT-1600, Germany and pH meter from Radio meter company model Ion Check were used. Diluter pipette model DIP-1 (Shimadzu), having 100 $\mu \mathrm{L}$ sample syringe and five continuously adjustable pipettes covering a volume range from 20-5000 $\mu \mathrm{L}$ (model PIPTMAN P, GILSON), an ultrasonic processor model powersonic 405, electronic balance (Sartorius-2474; $\mathrm{d}=0.01 \mathrm{mg}$ ), ash furnace at $100-1200{ }^{\circ} \mathrm{C}$ type Nabertherm and oven at $50-350{ }^{\circ} \mathrm{C}$ for treatment of bentonite were used.

Tetrahydroforan, dichloromethane, dimethyldichlorosilane, 1-bromophenyl, magnesium metal were purchased from Merck, Germany.

Preparation of thermal treatment and acidic washing for bentonite: Bentonite was crushed to obtain small pieces, which have diameter $(150-250 \mu \mathrm{m})$ and was thermally treated in two steps at $700{ }^{\circ} \mathrm{C}$ and then at $1000^{\circ} \mathrm{C}$. After each step was refluxed with $6 \mathrm{~N} \mathrm{HCl}$ at boiling point for $18 \mathrm{~h}$ to remove soluble oxides especially iron oxide. Then it was washed several times with distilled water and dried at $120^{\circ} \mathrm{C}$ for $3 \mathrm{~h}\left(\mathrm{~B}_{\mathrm{A}}\right)$.

Bentonite chlorination $\left(\mathbf{B}_{\mathrm{A}} \mathbf{C l}\right)$ : $30 \mathrm{~g}$ of washed bentonite $\left(\mathrm{B}_{\mathrm{A}}\right)$ is dispersed in $250 \mathrm{~mL}$ of dichloromethane and $10 \mathrm{~mL}$ of dimethyldichlorosilane. The mixture was left under reflux during $3 \mathrm{~h}$. The solvent was evaporated and the residue was dried at $280^{\circ} \mathrm{C}$ during $3 \mathrm{~h}$. The chlorinated product was kept under inert nitrogen atmosphere $\left(\mathrm{B}_{\mathrm{A}} \mathrm{Cl}\right)$, as the equation:

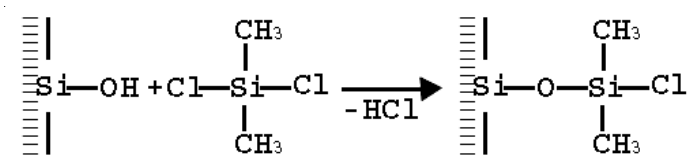

Preparation of phenyl-modified Aleppo bentonite $\left(B_{A}\right.$ phenyl): Phenyl magnesium bromide was prepared from reaction $10.6 \mathrm{~mL}$ of 1 - bromophenyl with $2.4 \mathrm{~g}$ of clean and dry magnesium in $200 \mathrm{~mL}$ of anhydrous tetrahydroforan (THF) as:

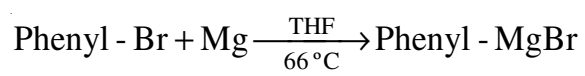

The solution of phenyl magnesium bromide was added to chlorinated bentonite $\left(\mathrm{B}_{\mathrm{A}} \mathrm{Cl}\right)$ under inert atmosphere $\left(\mathrm{N}_{2}\right)$. The mixture was allowed to reflux for $3 \mathrm{~h}$. Then the heating was removed and contents were allowed to cool. The produce was filtered and washed with methanol and dried at $105^{\circ} \mathrm{C}$ for $2 \mathrm{~h}$ ( $\mathrm{B}_{\mathrm{A}}$ phenyl), as the equation:

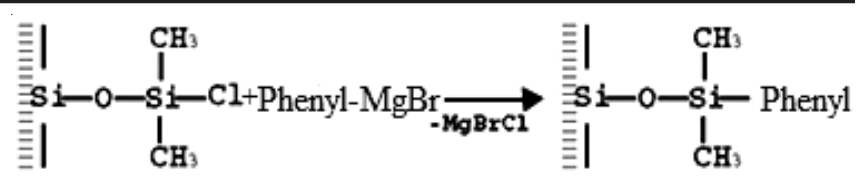

\section{RESULTS AND DISCUSSION}

Surface properties of $B_{A}$ and $B_{A}$ phenyl: Specific surface areas of $\mathrm{B}_{\mathrm{A}}$ and $\mathrm{B}_{\mathrm{A}}$ phenyl were determined by the adsorption of nitrogen at $77 \mathrm{~K}$ (BET). For determination of textural properties, the adsorption was carried out until near saturation $(\mathrm{P} / \mathrm{Po} \approx 1.0)$, then the desorption was completed until closure of the hysteresis loop. Representative adsorption-desorption isotherms of nitrogen for $\mathrm{B}_{\mathrm{A}}$ and $\mathrm{B}_{\mathrm{A}}$ phenyl are shown in Fig. 1. The isotherms are II and IV type of SING and BDDT classifications, which indicate the presence of mesoporous structure. Application of the linear BET equation to the nitrogen adsorption data was obtained within the range of relative pressures $(0.02-0.25)$ was as the follows: $y=0.36726 x+$ 0.0012 and $\mathrm{y}=1.035 \mathrm{x}+0.0029$ for $\mathrm{B}_{\mathrm{A}}$ and $\mathrm{B}_{\mathrm{A}}$ phenyl, respectively. BET specific surface areas $\left(\mathrm{S}_{\mathrm{BET}}\right)$ were 11.86 and $4.21 \mathrm{~m}^{2} / \mathrm{g}$, the total pore volume $\mathrm{v}_{\mathrm{p}}(0.0388$ and $0.01547 \mathrm{~mL} / \mathrm{g})$ was determined from the adsorbed volume at $\mathrm{P} / \mathrm{Po}=0.95$ in the liquid form and the mean pores radii $\mathrm{r}_{\mathrm{a}}(65.43$ and 73.49 $\AA$ ), was determined from the equation: $r_{\mathrm{a}}=2 \times 10^{4} \times \mathrm{v}_{\mathrm{p}} / \mathrm{S}_{\mathrm{BET}}$, for $\mathrm{B}_{\mathrm{A}}$ and $\mathrm{B}_{\mathrm{A}}$ phenyl, respectively. The variation of specific surface area, total pore volume and mean pores radii causing by grafting modification, as seen in Table- 1 .
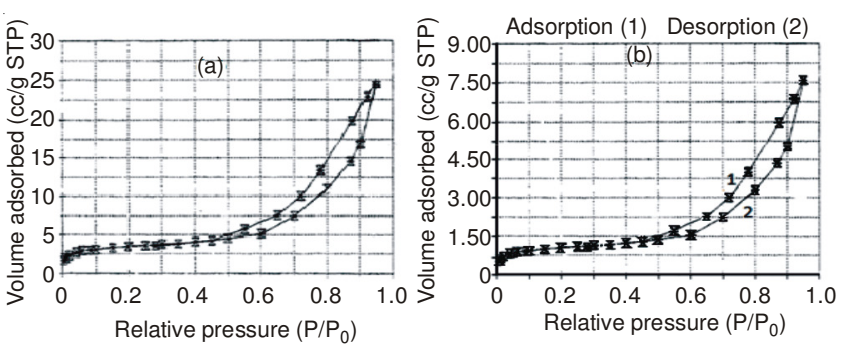

Fig. 1. Adsorption-desorption isotherm of nitrogen at $77 \mathrm{~K}$ on $\mathrm{B}_{\mathrm{A}}$ (a) and on $\mathrm{B}_{\mathrm{A}}$ phenyl (b)

TABLE-1 SURFACE PROPERTIES OF $B_{A}$ AND $B_{A}$ PHENYL

\begin{tabular}{cccc}
\hline Support & $\mathrm{S}_{\mathrm{BET}}\left(\mathrm{m}^{2} / \mathrm{g}\right)$ & $\mathrm{v}_{\mathrm{p}}(\mathrm{mL} / \mathrm{g})$ & $\mathrm{r}_{\mathrm{a}}(\AA)$ \\
\hline $\mathrm{B}_{\mathrm{A}}$ & 11.86 & 0.0388 & 65.43 \\
$\mathrm{~B}_{\mathrm{A}}$ Phenyl & 4.21 & 0.01547 & 73.49 \\
\hline
\end{tabular}

It was noticed that the specific surface area and the total pore volume were decreased from $\left(11.86 \mathrm{~m}^{2} / \mathrm{g}\right.$ and 0.0388 $\mathrm{mL} / \mathrm{g})$ to $\left(4.21 \mathrm{~m}^{2} / \mathrm{g}\right.$ and $\left.0.01547 \mathrm{~mL} / \mathrm{g}\right)$, respectively and the mean pores radii increased from 65.43 to $73.49 \AA$ (Table- 1 and Fig. 2).

Differential thermal analysis (DTA): A useful method for the characterization of $\mathrm{B}_{\mathrm{A}}$ and $\mathrm{B}_{\mathrm{A}}$ phenyl was measured by differential thermal analysis (DTA) technique in air atmosphere using $40 \mathrm{mg}$ bentonite with $\alpha-\mathrm{Al}_{2} \mathrm{O}_{3}$ as reference and heating rate $10^{\circ} \mathrm{C} / \mathrm{min}$. Fig. 3 shows that, the DTA traces of the $B_{A}$ and $\mathrm{B}_{\mathrm{A}}$ phenyl. It exhibited two endothermic peaks. The first appears at $145^{\circ} \mathrm{C}$, which is corresponding to the loss of water of hydration. The second, which occurred at about $610^{\circ} \mathrm{C}$, 


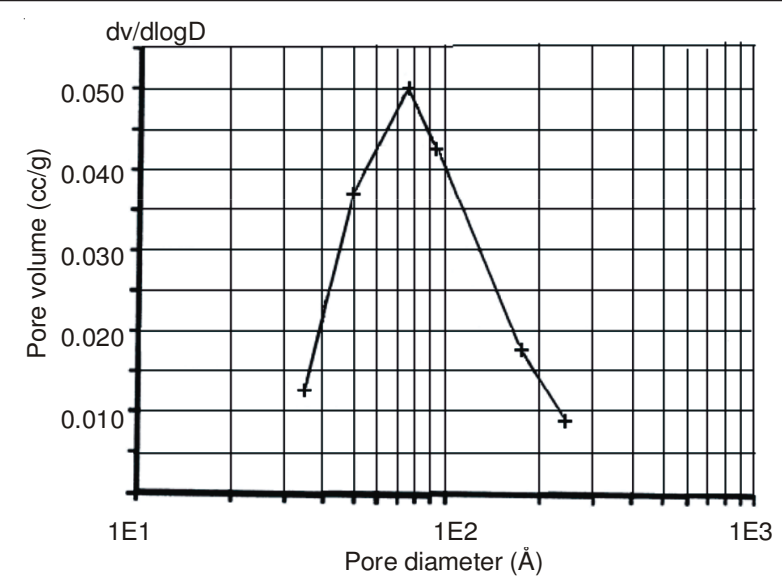

Fig. 2. Pore volume distribution of $B_{A}$ phenyl sample

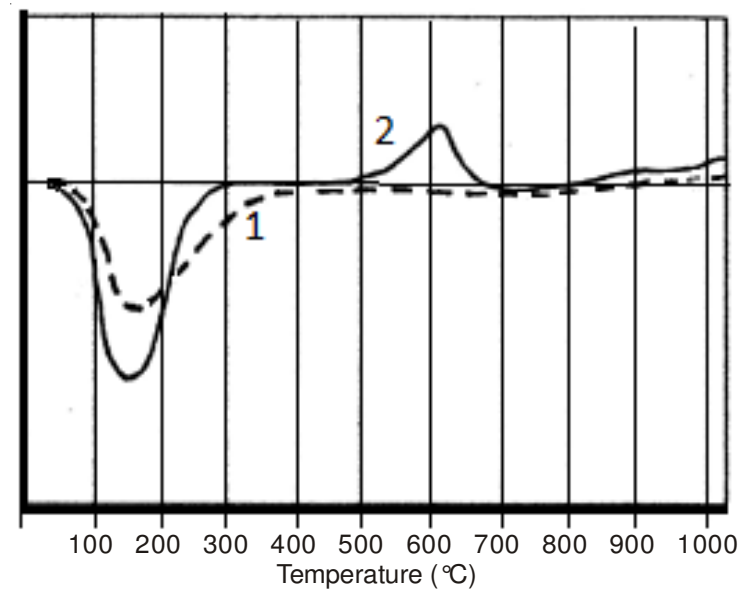

Fig. 3. Differential thermal analysis curve for $B_{A}$ (1) and $B_{A}$ phenylmodified (2). (in air atmosphere using $40 \mathrm{mg}$ bentonite with $\alpha$ $\mathrm{Al}_{2} \mathrm{O}_{3}$ as reference and heating rate $10^{\circ} \mathrm{C} / \mathrm{min}$ )

is related to the burning of hydrocarbon (phenyl) in $\mathrm{B}_{\mathrm{A}}$ phenyl support.

Hydrophobicity: Hydrophobicity estimation before and after modification, by comparing the dispersiblility of the $B_{A}$ and $\mathrm{B}_{\mathrm{A}}$ phenyl in water and benzene. Fig. 4 showed that the $\mathrm{B}_{\mathrm{A}}$ dispersing was in water layer only. By opposition, the presence of hydrophobic alkyl group on the external surface of $\mathrm{B}_{\mathrm{A}}$ phenyl, made the $\mathrm{B}_{\mathrm{A}}$ phenyl deposited in organic phase at the benzene-water.

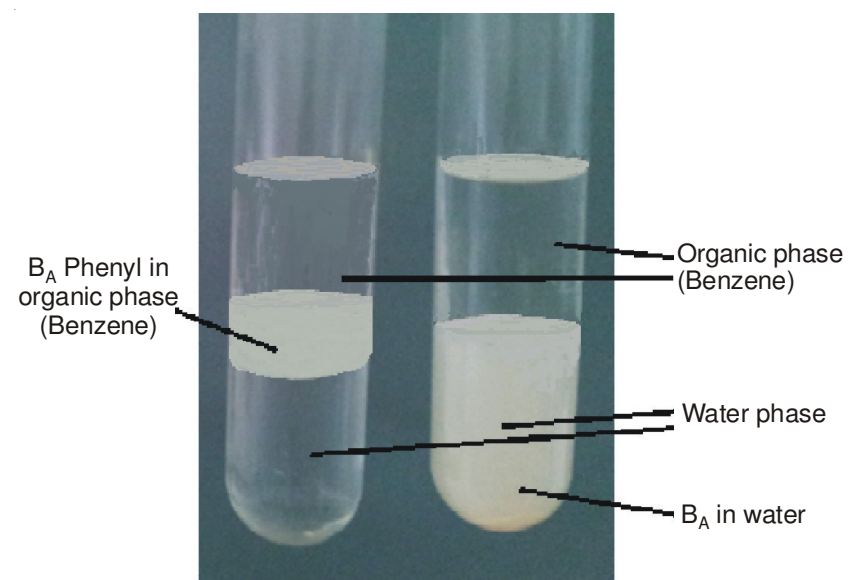

Fig. 4. $\mathrm{B}_{\mathrm{A}}$ (right) and $\mathrm{B}_{\mathrm{A}}$ phenyl (left) dispersed in water/benzene (organic phase) system
Plotting the relation between variation of the logarithm of retention volume and the reverse of absolute temperature $\log V_{s}=\mathbf{f}(\mathbf{1} / \mathbf{T})$ : The modification superficial structure of grafted $\mathrm{B}_{\mathrm{A}}$ phenyl compared to $\mathrm{B}_{\mathrm{A}}$ was studied by "inverse gas chromatographic method" in the range $40-110{ }^{\circ} \mathrm{C}$ and column dimension $(100 \mathrm{~cm} \times 4 \mathrm{~mm})$ using dichloromethane (polar), benzene (moderate polarity) and $n$-pentane (non-polar) as auxiliary solutes. The plotted relationship $\log \mathrm{V}_{\mathrm{s}}=\mathrm{f}(1 / \mathrm{T})$ shown that, a decreasing of volume retention was noticed with grafted bentonite by modification phenyl group compared to $\mathrm{B}_{\mathrm{A}}$ (Fig. 5). Fig. 5 shown that the three auxiliary solutes approve the modification of the superficial structure of the bentonite $\mathrm{B}_{\mathrm{A}}$ support surface.

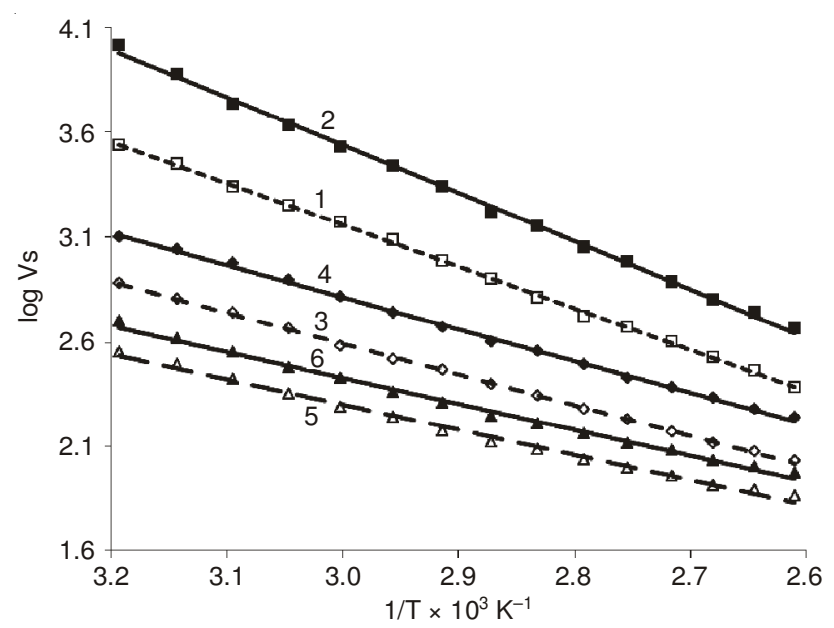

Fig. 5. Variation of $\log \mathrm{Vs}=\mathrm{f}(1 / \mathrm{T})$ on $(100 \mathrm{~cm} \times 4 \mathrm{~mm})$ packed columns using bare bentonite $\mathrm{B}_{\mathrm{A}}(2,4,6)$ and grafted bentonite $\mathrm{B}_{\mathrm{A}}$ phenyl $(1,3,5)$; benzene $(1,2)$; dichloromethane $(3,4) ; n$-pentane $(5,6)$

Identification of gasoline: An automatic method has been developed for the determination of gasoline components by gas chromatography using grafted Aleppo bentonite $\left(B_{A}\right.$ phenyl). The chromatographic conditions for analysis are as the following: analytical copper column $(100 \mathrm{~cm} \times 4 \mathrm{~mm})$ packed with $\mathrm{B}_{\mathrm{A}}$ phenyl, programmed column temperature between $35-215{ }^{\circ} \mathrm{C}$, with increasing temperature rate $3{ }^{\circ} \mathrm{C} /$ min, FID, flow rate of $\mathrm{N}_{2}$ carrier gas $35 \mathrm{~mL} / \mathrm{min}$, the injection volume $0.2 \mu \mathrm{L}$ and injected port temperature $190^{\circ} \mathrm{C}$. Fig. 6 shows the gasoline chromatogram. The analytical results were characterized by high precision, accuracy and reproducibility. The components groups of gasoline was given in Table-2.

TABLE-2

CARBON NUMBER OF COMPONENTS GROUPS IN GASOLINE

\begin{tabular}{cc}
\hline Carbon number (Identity) & Amount $(\%)$ \\
\hline Total $\mathrm{C}_{3}$ & 0.0008948 \\
Total $\mathrm{C}_{4}$ & 0.28 \\
Total $\mathrm{C}_{5}$ & 14.76 \\
Total $\mathrm{C}_{6}$ & 34.16 \\
Total $\mathrm{C}_{7}$ & 13.07 \\
Total $\mathrm{C}_{8}$ & 25.13 \\
Total $\mathrm{C}_{9}$ & 11.59 \\
Total $\mathrm{C}_{10}$ & 0.76 \\
Total & 99.75 \\
Total $\mathrm{C}_{5}-\mathrm{C}_{10}$ & 99.47 \\
\hline
\end{tabular}




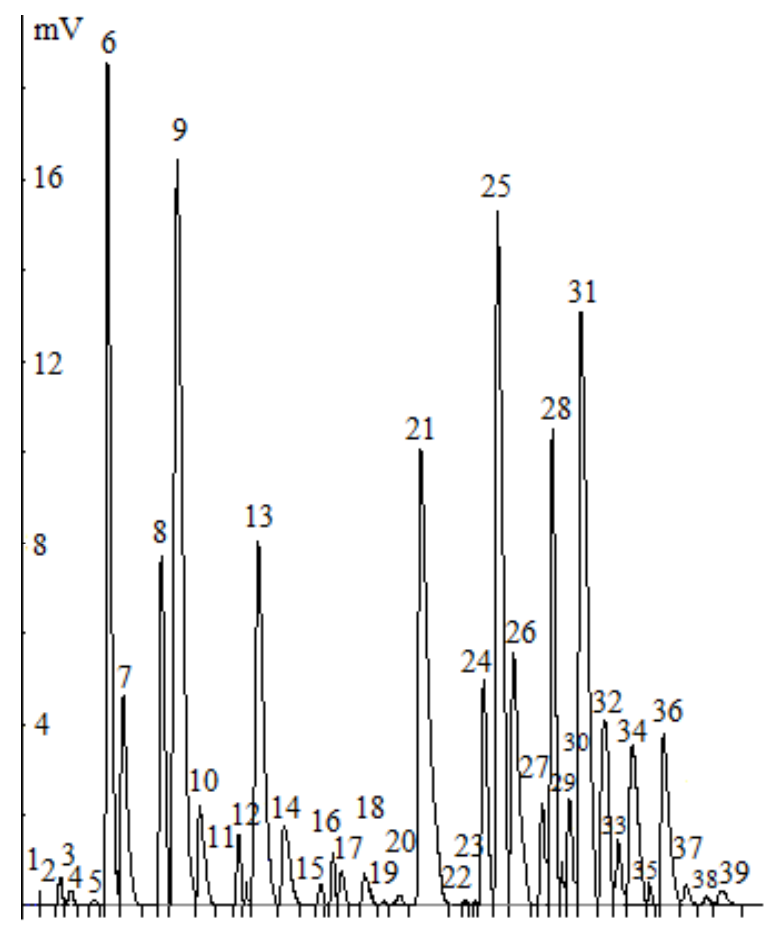

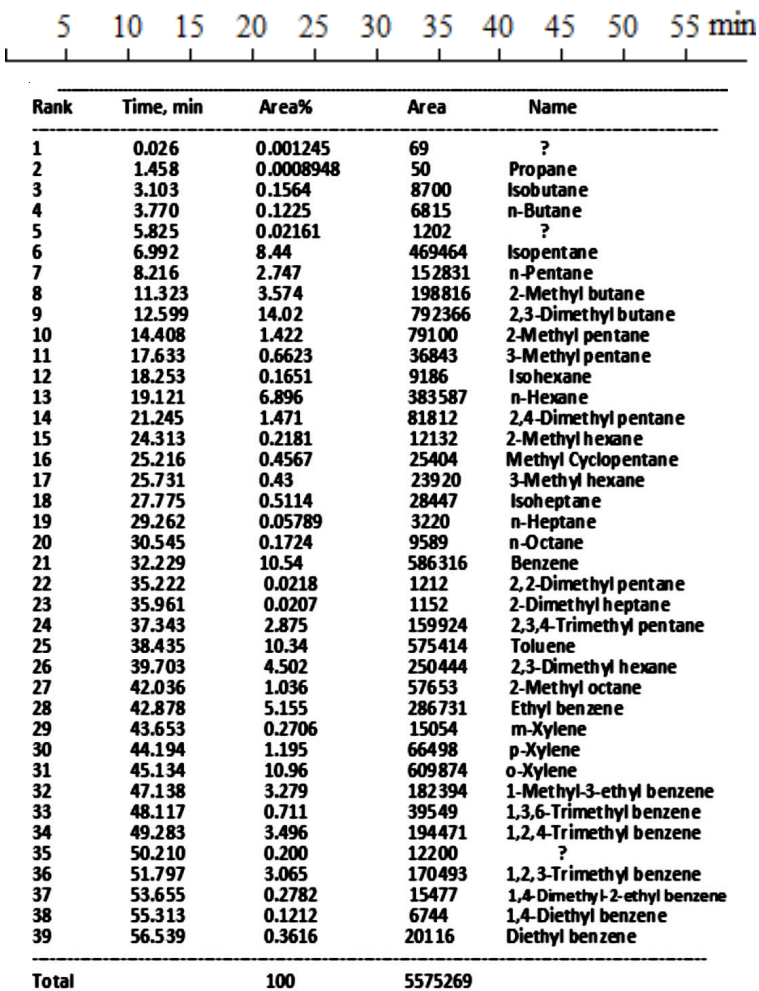

Fig. 6. Gas chromatographic analysis of gasoline components (Programmed column temperature between $35-215{ }^{\circ} \mathrm{C}$, with increasing temperature rate $3{ }^{\circ} \mathrm{C} / \mathrm{min}$, FID, flow rate of $\mathrm{N}_{2}$ carrier gas $35 \mathrm{~mL} / \mathrm{min}$, the injection volume $0.2 \mu \mathrm{L}$ and injected port temperature $190{ }^{\circ} \mathrm{C}$ )

Identification of lighter gas (as gas refill lighter): The lighter gas components of three gas refill lighter were determined by gas chromatography using grafted Aleppo bentonite ( $\mathrm{B}_{\mathrm{A}}$ phenyl). The following commercial types were subjected to the analytical procedures: Won Bao, Butane Gas Products Refill (155 mL), China. Can, Gaslighter (250 mL), Egypt. Campingman, Butane Gas (227 g), Korea.
The chromatographic conditions for analysis are as the following: analytical copper column $(100 \mathrm{~cm} \times 4 \mathrm{~mm})$ packed with $\mathrm{B}_{\mathrm{A}}$ phenyl, programmed column temperature between $35-215^{\circ} \mathrm{C}$, with increasing temperature rate $3{ }^{\circ} \mathrm{C} / \mathrm{min}$, FID, flow rate of $\mathrm{N}_{2}$ carrier gas $35 \mathrm{~mL} / \mathrm{min}$, the injection volume $250 \mu \mathrm{L}$ and injected port temperature $190{ }^{\circ} \mathrm{C}$. Fig. 7 shows that, the separation was completed with a high precision and reproducibility. The analytical results were characterized by high precision, accuracy and reproducibility. The carbon number of natural gas in studied gas refill lighter was observed in Table-3.
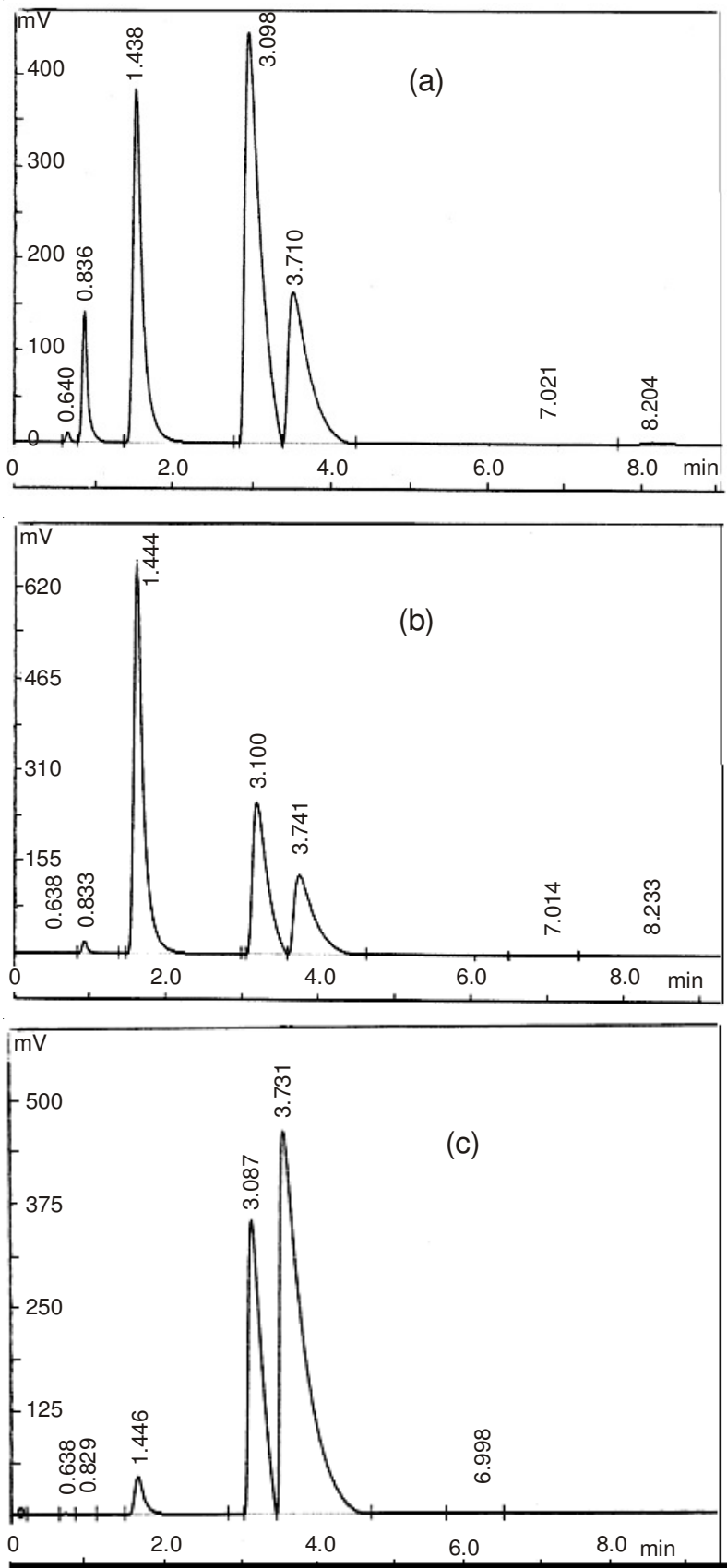

Fig. 7. Gas chromatographic analysis of natural gas components of three gas refill lighter: (a) Won Bao, Butane Gas Products Refill, China; (b) Can, Gaslighter, Egypt; (c) Campingman, Butane Gas, Korea (Programmed column temperature between $35-215^{\circ} \mathrm{C}$, with increasing temperature rate $3{ }^{\circ} \mathrm{C} / \mathrm{min}$, FID, flow rate of $\mathrm{N}_{2}$ carrier gas $35 \mathrm{~mL} / \mathrm{min}$, the injection volume $250 \mu \mathrm{L}$ and injected port temperature $190{ }^{\circ} \mathrm{C}$ ) 


\begin{tabular}{cccc}
\hline \multicolumn{4}{c}{ TABLE-3 } \\
CARBON NUMBER OF LIGHTER GAS \\
\hline \multicolumn{4}{c}{ IN STUDIED GAS REFILL LIGHTER } \\
\hline $\begin{array}{c}\text { Carbon number } \\
\text { (Identity) }\end{array}$ & $\begin{array}{c}\text { Wan Bao, } \\
\text { China (\%) }\end{array}$ & $\begin{array}{c}\text { Can, Egypt } \\
(\%)\end{array}$ & $\begin{array}{c}\text { Camping man, } \\
\text { Korea }(\%)\end{array}$ \\
\hline $\mathrm{C}_{1}$ (Methane) & 0.3305 & 0.002686 & 0.002658 \\
$\mathrm{C}_{2}$ (Ethane) & 5.367 & 0.9382 & 0.06606 \\
$\mathrm{C}_{3}$ (Propane) & 25.01 & 48.49 & 3.027 \\
$\mathrm{C}_{4}$ (Isobutene) & 45.75 & 29.03 & 29.44 \\
(n-Butane) & 22.76 & 20.88 & 67.27 \\
$\mathrm{C}_{5}$ (Isopentane) & 0.09771 & 0.08997 & 0.1474 \\
(n-Pentane) & 0.6776 & 0.5696 & - \\
Total & 99.993 & 100.00 & 99.953 \\
\hline
\end{tabular}

\section{Conclusion}

Phenyl-modified Aleppo bentonite ( $\mathrm{B}_{\mathrm{A}}$ phenyl) as support for $\mathrm{GC}$ was developed. The BET surface areas $\left(\mathrm{S}_{\mathrm{BET}}\right)$ for $\mathrm{B}_{\mathrm{A}}$ phenyl was $4.21 \mathrm{~m}^{2} / \mathrm{g}$, the total pore volume $\left(\mathrm{v}_{\mathrm{p}}\right)$ was 0.01547 $\mathrm{mL} / \mathrm{g}$ and the mean pores radii $\left(\mathrm{r}_{\mathrm{a}}\right)$ were $73.49 \AA$. Thirty six hydrocarbons components in gasoline and seven in lighter gas were determined by using $\mathrm{B}_{\mathrm{A}}$ phenyl as support in GCA. The principle gasoline components groups (total $\mathrm{C}_{5}$ to total $\mathrm{C}_{10}$ ) percent were presented as follows: $0.001,0.28,14.76,34.16$, $13.07,25.13,11.59$ and $0.76 \%$ and lighter gas per cent (propane, isobutane and $n$-butane) as follows: 3.03-48.49, 29.03-45.75 and 20.88-67.27\%, respectively.

\section{REFERENCES}

1. M. Lahmek, M.Sc. Thesis in Chemistry, Gas chromatographic analysis by using Aleppo bentonite columns, Aleppo University, Aleppo, Syria (1987).

2. A. Alhaj Sakur, M.Sc. Thesis in Chemistry, Gas chromatographic analysis using Aleppo bentonite columns deactivated by grafting, Aleppo University, Aleppo, Syria (1995).

3. A.A. Ramadan, S. Antakli and I. Mahmoud, Res. J. Aleppo Univ, , 55, 297 (2007).

4. M. Martini, M.Sc. Thesis in Chemistry, Chromatographic applications using Aleppo bentonite, Aleppo University, Aleppo, Syria (1990).
5. A. Alhaj Sakur, Ph.D. Thesis in Chemistry, Studying of some chromatographic supports prepared from bentonite and using it in chromatographic analysis, Aleppo University, Aleppo, Syria (2000).

6. T. Sahlabji, M.Sc. Thesis in Chemistry, Development of some chromatographic supports prepared from natural bentonite and using them in some gas chromatographic applications, Aleppo University, Aleppo, Syria (2003).

7. A.A. Ramadan, S. Antakli and I. Mahmoud, Res. J. Aleppo Univ., 56, 97 (2007).

8. O. Abdul Ghafour, M.Sc. Thesis in Chemistry, Thin layer chromatography using Aleppo bentonite, Aleppo University, Aleppo, Syria (1998).

9. I. Mahmoud, Ph.D. Thesis in Chemistry, Preparation of chromatographic supports and using them in thin layer chromatographic analysis, Aleppo University, Aleppo, Syria (2011).

10. A.A. Ramadan, A. Bodakji and I. Mahmoud, Asian J. Chem., 22, 3283 (2010).

11. ASTM D 4815-94a. Standard Test Method for MBTE, ETBE, TAME, DIPE, tertiary-Amyl Alcohol and C1 to C4 Alcohols in Gasoline by Gas Chromatography.

12. J.R. Durand, Y. Boscher, N. Petroff and M. Berthelin, J. Chromatogr. A, 395, 229 (1987).

13. ASTM D 3710-93. Standard Test Method for Boiling Range Distribution of Gasoline and Gasoline Products by Gas Chromatography.

14. ASTM D 2887-93. Standard Test Method for Boiling Range Distribution of Petroleum Fractions by Gas Chromatography.

15. S.V. Cherepitsa, S.M. Bychkov, S.V. Gatsikha, A.N. Kovalenko, A.L. Mazanik, D.E. Kuzmenkov, Ya.L. Luchinina and N.N. Gremyako, Chem. Technol. Fuels Oils, 37, 283 (2001).

16. J.P. Durand, Y. Boscher, N. Petroff and M. Berthelin, J. Chromatogr. A, 395, 229 (1987)

17. D.H. Desty, A. Goldup and W.T. Swanton, in eds: N. Brenner, J.E. Callen and M.D. Weiss, Gas Chromatography, Academic Press, New York, p. 105 (1962).

18. W.N. Sanders and J.B. Maynard, Anal. Chem., 40, 527 (1968).

19. J. Balakrishnan and V. Balasubramanian, J. Appl. Chem. Res., 18, 69 (2011).

20. F.S. de Oliveira, L.S. Gomes Teixeira, M.C. Ugulino Araujo and M. Korn, Fuel, 83, 917 (2004).

21. N. Ré-Poppi, F.F.P. Almeida, C.A.L. Cardoso, J.L. Raposo Jr., L.H. Viana, T.Q. Silva, J.L.C. Souza and V.S. Ferreira, Fuel, 88, 418 (2009).

22. J.B. Hooper, J.V. Thomas, D.L. Sutton, K.A. Lintelmann, R.J. Trocino and R.P. Philp, Anal. Chem., 65, 171 (1993).

23. A.S. Brown, M.J.T. Milton, C.J. Cowper, G.D. Squire, W. Bremser and R.W. Branch, J. Chromatography A, 1040, 215 (2004). 